\title{
Um instrumento para a análise das percepções/ações de estudantes em sala de aula
}

\section{RESUMO}

Sergio de Mello Arruda sergioarruda@sercomtel.com.br 0000-0002-4149-2182 Universidade Estadual de Londrina, Paraná, Brasil

Marily Aparecida Benício marily.benicio@ifpr.edu.br

0000-0002-2790-7425

Instituto Federal do Paraná, Telêmaco Borba, Paraná, Brasil

\section{Marinez Meneghello Passos} marinezmp@sercomtel.com.br 0000-0001-8856-5521 Universidade Estadual de Londrina, Paraná, Brasil
Este artigo tem como objetivo apresentar um instrumento de pesquisa que permite investigar as relações com o saber de estudantes em sala de aula. $O$ instrumento, denominado de Matriz do Estudante, trata a sala de aula como um sistema complexo de relações epistêmicas, pessoais e sociais com o conteúdo a ser ensinado, com o ensino desenvolvido pelo professor e com a aprendizagem dos estudantes. Embora de caráter mais teórico, o artigo também apresenta dados coletados com estudantes de um dos campi do Instituto Federal do Paraná. Os dados apresentados neste artigo, no entanto, têm o objetivo de prover consistência experimental às argumentações que dão suporte teórico ao instrumento. $\mathrm{O}$ artigo finaliza com os descritores de cada uma das nove células da matriz e com um conjunto de questões orientadoras para pesquisas futuras.

PALAVRAS-CHAVE: Relação com o saber. Triângulo didático-pedagógico. Matriz do estudante. 


\section{INTRODUÇÃO}

A questão de entender o que é a aprendizagem é um dos mais complexos tópicos da educação. A Enciclopédia Internacional da Educação, uma das mais importantes e abrangentes publicações na área, dedica grande parte de seu volume 5 ao assunto Aprendizagem e Cognição, cobrindo temas como: aprendizagem na infância, inteligência, memória, metacognição, aprendizagem de adultos, cognição e emoção, desenvolvimento da criatividade, resolução de problemas, bases neurocientíficas da aprendizagem, aquisição da linguagem, aprendizado da Matemática e da música, Piaget, Vygotsky, construtivismo, aprendizagem e gênero, aprendizagem fora da escola, perspectivas socioculturais da aprendizagem, etc. (PETERSON; BAKER; McGAW, 2010). A grande quantidade de verbetes presentes no campo da aprendizagem encontrados nessa Enciclopédia confirma, como escreve Illeris, que, além de não haver uma definição única do conceito de aprendizagem aceita por todos, há uma grande variedade de teorias, abordando a questão por diferentes ângulos (ILLERIS, 2013, p. 7, 15).

Nesse artigo optamos por abordar a aprendizagem como uma "prática do saber" (CHARLOT, 2005a, p. 93). Em síntese, o termo significa que para aprender é preciso se envolver em uma prática, entendida como uma ação direcionada e contextualizada, cuja finalidade "é construir um mundo coerente de saberes" (ibid, p. 93). A posição de Charlot é compatível com a de Lave, quando a autora diz que (LAVE, 2013, p. 236):

É difícil, ao olhar detalhadamente as atividades cotidianas, fugir da conclusão de que a aprendizagem é onipresente nas atividades contínuas, embora, muitas vezes, não seja reconhecida como tal. A atividade situada sempre envolve mudanças no conhecimento e na ação, e as 'mudanças no conhecimento e na ação' são centrais ao que queremos dizer com 'aprendizagem'.

Transpondo essa visão para a sala de aula, não poderíamos deixar de concordar com Charlot quando ele escreve que "no centro fica a prática do aluno e não a prática docente" (CHARLOT, 2005b, p. 96).

Em função da ideia da aprendizagem como prática do saber o presente artigo tem como objetivo apresentar um instrumento que permite a análise das percepções e/ou ações de um estudante sobre sua própria aprendizagem, sobre o professor e seu ensino e sobre as relações do professor com os saberes escolares e profissionais. O instrumento - denominado de Matriz do Estudante fundamenta-se na temática das relações com o saber e em um modelo representacional da sala de aula, a respeito dos quais discorreremos na próxima seção.

\section{A RELAÇÃO COM O SABER NA SALA DE AULA}

Já há algum tempo temos tomado a temática da relação com o saber (CHARLOT, 2000) como ponto de partida, para analisar a formação de professores, o ensino e a aprendizagem de ciências, tanto em situações educativas formais como informais. A relação com o saber é definida, essencialmente, como "uma forma da relação com o mundo" (CHARLOT, 2000, p. 77) ou ainda como "a relação do sujeito com o mundo, com ele mesmo e com os outros" (CHARLOT, 2000, p. 78). 
Se a sala de aula é o foco da investigação podemos entender a relação com o mundo como a relação do sujeito com o mundo escolar, isto é, com um local com finalidades específicas, o campo em que estão presentes os saberes escolares, definidos pelos currículos; os atores deste ambiente, como os alunos, os professores, os administradores e orientadores educacionais deste local (diretores, supervisores, pedagogos) etc.; e toda a parte física deste mundo (o prédio, as salas de aula, as carteiras, os equipamentos, laboratórios etc.).

Para esse mundo assim especificado, podemos classificar as relações com o saber em três tipos principais: relações epistêmicas, pessoais e sociais com o saber, conforme definidas a seguir:

a) Relação epistêmica: entendemos que a observação do mundo neste registro coloca questões puramente intelectuais ou cognitivas, do tipo sei/não sei, conheço/não conheço, compreendo/não compreendo etc., que remetem à existência de um saber objetivo e independente, ou, como diria Popper, a um "conhecimento sem sujeito que conheça" (POPPER, 1975, p. 111).

b) Relação pessoal: relaciona-se a questões do tipo gosto/não gosto, quero/não quero, sinto/não sinto etc., remetendo a sentimentos, emoções, sentidos, desejos e interesses de um ser humano considerado como individualidade física e espiritual, dotado de autoconsciência e capacidade para agir, pensar e sentir.

c) Relação social: diz respeito às demandas, valores, acordos, preceitos, crenças, leis, que têm origem nos grupamentos e comunidades em que vivem os indivíduos, remetendo a questões do tipo valorizo/não valorizo, devo/não devo (fazer), posso/não posso (sou ou não autorizado a fazer) etc.

Essa classificação foi adaptada das definições originais de Charlot (2000) a respeito das "relações epistêmicas", "de identidade" e "social" com o saber (CHARLOT, 2000, p. 68-74). Mas nós as estamos utilizando como categorias gerais de análise e interpretação de dados. A separação entre essas três categorias é um tanto artificial, dado que a realidade surge indivisível perante nós. Mas a separação da realidade em partes é, parcialmente, justificada por se constituir como uma fonte de produção de novas ideias e reflexões a respeito desta realidade.

Embora os três registros estejam sendo entendidos como três modos distintos de relação do sujeito com o mundo, nós estamos particularmente interessados nas relações do sujeito com o saber em uma sala de aula. Mas, o que é uma sala de aula?

O primeiro modelo de uma sala de aula, ou, de um modo mais geral, da relação educativa, também denominado modelo canônico (GAUTHIER; TARDIF, 2013, p. 41), constituiu-se a partir de Platão, dentro das transformações pelas quais passaram as ideias e as práticas pedagógicas a partir de Sócrates. Na antiguidade grega o que importava na relação educativa era a comunicação entre o mestre e os aprendizes. A ênfase do ensino, antes situada na discussão, no diálogo e na relação verbal entre o educador e o educando, passou, após Sócrates, para a relação entre o educador, o educando e um saber objetivo e universal, independente do sujeito. Nesse modelo (GAUTHIER; TARDIF, 2013, p. 41): 
O modelo canônico pode ser considerado o primeiro modelo de uma sala de aula padrão, também chamado de "triângulo didático" ou "triângulo pedagógico" (GAUTHIER et al., 2006, p. 172, nota de rodapé). Neste artigo utilizaremos o termo triângulo didático-pedagógico (ou abreviadamente triângulo) para nos referirmos a esse sistema - o triângulo da Figura 1 - no qual: $E$, representa os estudantes que formam a classe, ou apenas um deles; $\mathrm{P}$, é o professor; e $\mathrm{S}$ é o saber, muitas vezes considerado apenas como o conteúdo a ser ensinado.

Figura 1 - Triângulo didático-pedagógico

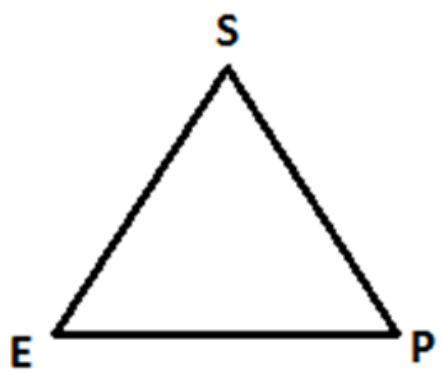

(Fonte: os autores)

Estamos interessados, nesse momento, principalmente nas relações com o saber no interior desse triângulo representativo da sala de aula.

Além dos pontos E, P e S, fazem parte da Figura 1 os segmentos E-P, E-S e P-S, que exigem comentários adicionais para serem devidamente compreendidos. $\mathrm{O}$ segmento E-P representa a relação que o estudante estabelece com o sujeito $P$, enquanto seu professor; trata-se, portanto, do ensino, conforme percebido pelo estudante. O segmento E-S representa a relação que o estudante estabelece com o saber S, enquanto uma disciplina, um conteúdo, um conceito etc., o que estamos interpretando como a aprendizagem, conforme percebida e/ou praticada pelo estudante. Finalmente, o segmento P-S representa a relação que o professor estabelece com o saber, enquanto uma disciplina, um conteúdo, um conceito etc.: trata-se, portanto, da aprendizagem do professor, enquanto profissional da educação, conforme percebida pelo estudante.

Cabe lembrar que, se as arestas forem pensadas isoladamente, elas poderiam não ter relação alguma com a sala de aula. E-P poderia significar apenas a relação entre duas pessoas E e P, independentemente de elas serem, respectivamente, estudante e professor ou da existência de um saber escolar $\mathrm{S}$, que as vincula. E-S poderia representar a relação de uma pessoa $E$ com um saber $S$, independentemente se há um professor ou se essa aprendizagem refere-se à educação escolar. P-S poderia representar a relação entre um sujeito $\mathrm{P}$ e um saber $\mathrm{S}$, independentemente se $\mathrm{P}$ é um professor ou se $\mathrm{S}$ é um saber a ser ensinado na escola.

É importante observar - e isso tem relevância para a tomada e análise de dados de pesquisa em sala de aula - que o triângulo didático-pedagógico da Figura 1 oferece três ângulos de observação: o do estudante (ponto E), o do professor (ponto P) e o do saber (ponto S). A maneira de interpretar as ações que ocorrem durante a circulação dos saberes no triângulo é diferente se observada pelo olhar 
do estudante E (aprendizagem), pelo olhar do professor P (ensino), ou pelo "olhar" do saber S (currículo). Ou seja, é possível investigar o funcionamento didáticopedagógico do triângulo observando a ação dos agentes em sala de aula: tanto a ação do professor, como a ação do estudante ou a "ação" do saber.

Para o estudante, por exemplo, as relações E-P, E-S e P-S vêm sempre tingidas pela sua posição em um triângulo didático-pedagógico que não está isolado, que se encontra aberto à instituição e à própria sociedade na qual está inserido. Neste triângulo $\mathrm{E}$ é o estudante, o sujeito que aprende, que estabelece relações com o conteúdo, que monitora sua aprendizagem e que tem certa visão de si mesmo, enquanto pessoa. É também um ser em formação à procura de um lugar no mundo e de sua própria subsistência. Por outro lado, P, o professor, é aquele que ensina, que faz a mediação entre o estudante e o saber, e que mantém com o estudante relações interpessoais. O estudante observa o comportamento do professor (e do professor enquanto pessoa) tanto na sala de aula, quanto fora dela. Observa sua relação com o ensino (como o professor ensina), com o curso e com a profissão. Por fim, o saber, neste caso, nem sempre é o puro conteúdo disciplinar, pois está muitas vezes diretamente relacionado ao trabalho, principalmente no caso dos sujeitos desta pesquisa: trata-se, portanto, de um saber escolar e profissional.

Nesse sentido, o problema fundamental de que trata esse artigo - um problema triplo, na verdade - é o de determinar quais são as percepções/ações do estudante a respeito de três pontos:

(i) do ensino praticado pelo professor (segmento E-P) do ponto de vista epistêmico, pessoal e social. Ou seja, o que o estudante sabe, sente e valoriza a respeito desse ensino e quais ações ele desenvolve em sala de aula, relacionadas a esse segmento?

(ii) dos saberes escolares e/ou profissionais e de sua própria aprendizagem (segmento E-S) do ponto de vista epistêmico, pessoal e social. Ou seja, o que o estudante sabe, sente e valoriza a respeito dos saberes escolares e/ou profissionais e de sua aprendizagem e quais ações ele desenvolve em sala de aula, relacionadas a esse segmento?

(iii) da relação do professor com os saberes escolares e/ou profissionais (segmento P-S) do ponto de vista epistêmico, pessoal e social. Ou seja, o que o estudante sabe, sente e valoriza a respeito da relação do professor com os saberes escolares e/ou profissionais e quais ações ele desenvolve em sala de aula, relacionadas a esse segmento?

A matriz 3x3, descrita na próxima seção, foi elaborada como parte do processo de resolução do conjunto de questões mencionados acima.

\section{A MATRIZ DO ESTUDANTE}

Considerando o exposto na seção anterior, o passo seguinte da nossa pesquisa consistiu em aplicar as relações com o saber, definidas pelos registros epistêmico, pessoal e social, ao triângulo didático-pedagógico da Figura 1. Isso adiciona três dimensões ao triângulo que se transforma no prisma da Figura 2: 


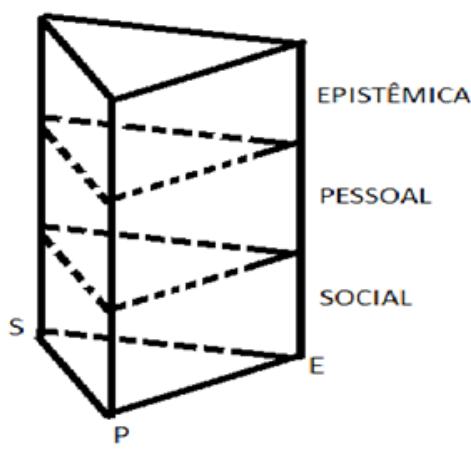

(Fonte: Arruda; Passos, 2015)

É fácil perceber que, se abrirmos o prisma da Figura 2, ele forma uma matriz tendo como colunas as arestas E-P, E-S e P-S e como linhas as relações epistêmicas, pessoais e sociais com o saber, conforme mostrado nos Quadros 1 e 2, a seguir.

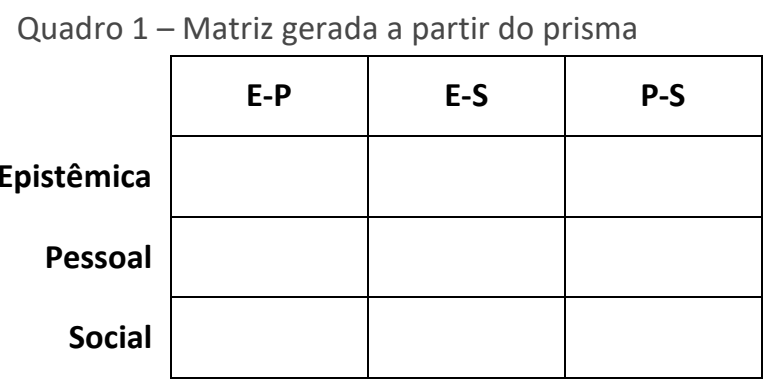

(Fonte: Arruda; Passos, 2015)

Levando em consideração o Quadro 1, bem como o problema de pesquisa desse artigo definido na seção anterior, obtemos uma matriz $3 \times 3$, que estamos denominando por Matriz do Estudante, representada no Quadro 2. 
Quadro 2-Matriz do Estudante

\begin{tabular}{|c|c|c|c|}
\hline $\begin{array}{l}\text { Percepções/ações } \\
\text { dostudante } \\
\text { Relações } \\
\text { com o saber }\end{array}$ & $\begin{array}{c}1 \\
\text { a respeito do } \\
\text { professor e seu } \\
\text { ensino } \\
\text { (segmento E-P) }\end{array}$ & $\begin{array}{c}2 \\
\text { a respeito de sua } \\
\text { aprendizagem } \\
\text { (segmento E-S) }\end{array}$ & $\begin{array}{c}3 \\
\text { a respeito da relação do } \\
\text { professor com os saberes } \\
\text { escolares/profissionais } \\
\text { (segmento P-S) }\end{array}$ \\
\hline $\begin{array}{c}\text { a } \\
\text { Epistêmica } \\
\text { (conhecimento) }\end{array}$ & $\begin{array}{c}\text { Célula 1a } \\
\text { Diz respeito ao } \\
\text { pensamento do } \\
\text { estudante sobre o } \\
\text { ensino praticado } \\
\text { pelo professor }\end{array}$ & $\begin{array}{c}\text { Célula 2a } \\
\text { Diz respeito ao } \\
\text { pensamento do estudante } \\
\text { sobre os saberes } \\
\text { escolares/profissionais e à } \\
\text { sua própria aprendizagem }\end{array}$ & $\begin{array}{c}\text { Célula 3a } \\
\text { Diz respeito ao } \\
\text { pensamento do estudante } \\
\text { sobre a relação do } \\
\text { professor com os saberes } \\
\text { escolares/profissionais }\end{array}$ \\
\hline $\begin{array}{c}\text { b } \\
\text { Pessoal } \\
\text { (sentido) }\end{array}$ & $\begin{array}{c}\text { Célula } 1 \mathrm{~b} \\
\text { Diz respeito ao } \\
\text { sentido que o } \\
\text { estudante atribui ao } \\
\text { ensino praticado } \\
\text { pelo professor }\end{array}$ & $\begin{array}{c}\text { Célula } 2 b \\
\text { Diz respeito ao sentido } \\
\text { que o estudante atribui } \\
\text { aos saberes } \\
\text { escolares/profissionais e à } \\
\text { sua própria aprendizagem }\end{array}$ & $\begin{array}{c}\text { Célula } 3 b \\
\text { Diz respeito ao sentido que } \\
\text { o estudante atribui à } \\
\text { relação do professor com } \\
\text { os saberes } \\
\text { escolares/profissionais }\end{array}$ \\
\hline $\begin{array}{c}\text { c } \\
\text { Social } \\
\text { (valor) }\end{array}$ & $\begin{array}{c}\text { Célula } 1 c \\
\text { Diz respeito ao valor } \\
\text { que o estudante } \\
\text { atribui ao ensino } \\
\text { praticado pelo } \\
\text { professor }\end{array}$ & $\begin{array}{c}\text { Célula } 2 \mathrm{c} \\
\text { Diz respeito ao valor que o } \\
\text { estudante atribui aos } \\
\text { saberes } \\
\text { escolares/profissionais e à } \\
\text { sua própria aprendizagem }\end{array}$ & $\begin{array}{c}\text { Célula } 3 c \\
\text { Diz respeito ao valor que o } \\
\text { estudante atribui à relação } \\
\text { do professor com os } \\
\text { saberes } \\
\text { escolares/profissionais }\end{array}$ \\
\hline
\end{tabular}

(Fonte: os autores)

Passemos, a seguir, à descrição do contexto, sujeitos e metodologia da pesquisa e, em seguida, para a apresentação e interpretação dos dados.

\section{CONTEXTO, SUJEITOS E METODOLOGIA}

Os dados desta investigação foram obtidos por meio de entrevistas realizadas com seis estudantes do terceiro ano dos cursos de Mecânica e Florestas do Ensino Médio e Técnico Integrado de uma das unidades do Instituto Federal do Paraná (IFPR), no ano de 2016. Os alunos relataram sobre a vida escolar, as impressões que haviam construído ao longo dos anos escolares, em relação às interações estabelecidas no espaço educacional.

Os cursos de Ensino Médio e Integrado são cursos com duração de três a quatro anos. O termo Integrado refere-se ao fato de que, além de o estudante cursar as componentes curriculares do Ensino Médio, cursará concomitantemente as componentes curriculares da formação técnica profissional. Com a conclusão, o formando obtém diploma de Técnico de Nível Médio.

As entrevistas realizadas tiveram como direcionamento a seguinte pergunta: Como foi sua vida escolar? Comente sobre ela. A partir dessa primeira questão, outras foram sendo realizadas conforme a necessidade de algum esclarecimento, aprofundamento ou encaminhamento da entrevista. Com a realização da transcrição, buscou-se encontrar nos fragmentos das falas dos alunos suas percepções sobre as relações existentes no contexto escolar, dentro da perspectiva fornecida pela Matriz do Estudante. 
Para a compreensão e interpretação dos dados foram utilizados os procedimentos da Análise Textual Discursiva (ATD), que é um método de análise de informações de natureza qualitativa. A ATD pode ser entendida como um processo auto-organizado de compreensão e de construção de novos conhecimentos, os quais emergem a partir de uma sequência recursiva de três elementos: desmontagem do texto, o estabelecimento de relações entre as unidades e a captação do novo emergente (MORAES; GALIAZZI, 2007).

A desmontagem dos textos é a primeira componente do processo da ATD; nela ocorre a desconstrução e unitarização do texto. Todos os documentos ou textos, produzidos ou já existentes, formam um conjunto de análise chamado de corpus. Esse material é decomposto em elementos constituintes - as unidades de análise - cada um deles assumindo um significado mais completo possível em si próprio.

A segunda etapa do processo de análise é o estabelecimento de relações, também chamado de processo de categorização. A categorização pode surgir da comparação constante entre as unidades de análises, da qual surgem as categorias denominadas de emergentes. Quando as categorias são organizadas mediante um referencial teórico escolhido previamente, são denominadas de a priori.

A terceira fase da análise é a captação do novo emergente, em que se busca expressar as compreensões atingidas. Nesta fase se constrói os metatextos, que são produções iniciais, inacabadas, que necessitam ser completadas por meio de crítica constante. No nosso caso o principal metatexto a ser construído são os descritores das células, em que cada uma delas será detalhada e explicada, complementando a matriz do Quadro 2.

\section{DADOS E ANÁLISES}

É preciso deixar claro que a matriz do Quadro 2 é uma hipótese, uma proposta de um instrumento de pesquisa que permite a categorização das falas e ações dos estudantes em sala de aula. Nesse sentido, os dados apresentados neste artigo têm o objetivo de prover consistência experimental às argumentações teóricas discutidas nas seções anteriores.

Optamos por apresentar as falas dos estudantes, agrupadas por células começando pela coluna 1. Inicialmente, faremos uma breve descrição da célula e um resumo das percepções dos estudantes que servirão de base para a elaboração dos descritores, apresentados na próxima seção. As falas, intercaladas por comentários explicativos, foram extraídas das entrevistas, transformando-se em unidades de análise. Elas estão apresentadas na forma [estudante] fala, conforme mostrado na continuidade. Embora isoladas, as frases compõem o discurso que o estudante fez durante a entrevista que sempre desliza de um registro a outro, de uma célula a outra da matriz.

Percepções/ações dos estudantes a respeito do professor e seu ensino (coluna 1)

Na coluna 1 foram alocadas as percepções dos estudantes a respeito do professor e seu ensino (segmento E-P) sob três perspectivas: epistêmica na célula $1 \mathrm{a}$; pessoal, na célula $1 \mathrm{~b}$; e social, na célula $1 \mathrm{c}$.

\section{Célula 1a}


A célula 1a diz respeito ao pensamento do estudante sobre o ensino praticado pelo professor. O estudante compara a ação de um professor com outro, de instituições diferentes ou da mesma instituição, e procura compreender os procedimentos didático-pedagógicos adotados por eles. Vamos a algumas falas:

[E1] Agora você chega no Instituto, você está com dúvida eles tiram suas dúvidas, eles falam venham pro horário de atendimento. São completamente diferentes das escolas que eu passei.

[E2] Porque ali [Ensino Fundamental] é tudo muito diferente daqui [Instituto]. Porque são instituições diferentes. Diferente assim: aqui eles criam pro mundo, lá eles criam pro mundinho deles. Então é tudo ali fechadinho, não tem que confrontar com nada. Aqui não... [Aqui] ninguém vai ficar correndo atrás de você. Dão oportunidades, muitas, mas ninguém segura a sua mão pra você fazer as coisas. Você tem que buscar você mesmo. E lá é diferente, se for preciso eles pegam na sua mão pra você fazer as coisas.

Quase todos os estudantes entrevistados demonstraram perceber as diferenças institucionais e de comportamento dos professores que tiveram no Ensino Fundamental e os professores com os quais conviviam no momento da entrevista (Instituto). Os professores são "completamente diferentes" (E1), as instituições são diferentes (E2) e "ninguém segura a sua mão para você fazer as coisas" (E2). Em ambos os casos trata-se de frases que avaliam o comportamento geral dos professores de instituições diferentes, as quais podem ser localizadas na célula [1a].

[E5] Os professores aqui são assim. No mínimo, porque assim tem amizades fortes aqui. Cria-se um laço de amizade legal com os professores. É questão de confiança, porque a gente fica o dia inteiro aqui... Essa convivência cria um laço de confiança, né?

O estudante E5 também percebe as diferenças, todavia enfatiza mais o relacionamento pessoal, a confiança que tem em relação aos professores do Instituto. Apenas com a convivência, com a observação e reflexão que os estudantes passam a entender o comportamento dos professores, como relata E1:

[E1] Mas depois de um tempo eu percebi que o [professor] MA só queria o melhor pra gente. Porque ele falava "copie e façam os exercícios", mas na última aula ele explicou tudo, o porquê dele fazer daquele jeito.

Ainda no registro epistêmico, nos depoimentos que se seguem, os estudantes comentaram seguidamente o "método" ou o "sistema" de ensino de seus professores. Eles demonstram perceber quando o método funciona ou não (pelo menos para cada um, individualmente, como relata E4), ou quando os professores não conseguem realizar satisfatoriamente a gestão de classe (E5). Fica claro também que é desejável que o professor procure explicar ao estudante porque faz o que faz. não dá certo é o sistema do professor RJ. Ele dá em um sistema em que você tem que ler o livro, tentar entender e fazer os exercícios. Eu acho que esse método daria mais certo em uma licenciatura, porque daí o aluno vai tentar buscar o melhor jeito de fazer isso. [...] O [professor] LU tem um jeito de passar bem interessante; ele pensa sempre em colocar mais na realidade e ele consegue... contextualizar, coisa assim de cálculo de seno e cosseno; ele deixou assim de um jeito bem fácil. 
[E5] Porque embora os professores fossem legais, principalmente no Ensino Fundamental, que fossem alguns professores legais, eu via que muita coisa, eles ficavam perdidos assim pra ensinar pra gente, entende? Ou às vezes eles ficavam perdidos assim em como lidar com a sala e, nossa, vindo aqui [no Instituto] mudou completamente a minha mentalidade sobre o professor.

\section{Célula 1b}

A célula 1 b diz respeito ao sentido que o estudante atribui ao ensino praticado pelo professor. O estudante avalia tanto o relacionamento pessoal com o professor, quanto o ensino praticado por ele em termos de afetos, emoções e sentimentos.

[E1] Professores assim foram bastante que me ajudaram. Mas, no começo tem uma professora da quarta série, que eu acho que ela me deu, da terceira e quarta série que ela foi muito amiga. Me ajudou bastante, eu lembro que eu gostava bastante dela.

[E2] Sempre gostei dos professores de lá [do Ensino Fundamental]. Um professor de Matemática. Nossa era meu xodó. Gosto muito dele. Ele me influenciou bastante.

[E5] Lá [no Ensino Fundamental] eu tinha duas professoras, mas eu lembro até hoje mais de uma, que era muito legal comigo. Ela me lembrava muito a Xuxa, que ela era loirinha e tinha o cabelinho, né.

A maioria dos estudantes quando perguntada sobre seus professores responde por meio das palavras gosto/não gosto. Em um primeiro momento eles se referem ao relacionamento pessoal com o(a) professor(a): era "amiga" (E1), era o "meu xodó" (E2) ou era muito "legal" (E5). Contudo, muitas vezes, os estudantes também se referem à ação didático-pedagógica do professor, ou seja, se gostam ou não do ensino que ele pratica, da maneira como ele atende e ajuda a resolver as dúvidas do estudante, como nos casos a seguir:

[E3] O [professor] SA era um cara muito gente boa e ele tinha o atendimento dele, e ele fazia de um jeito que parecia que você estava entendendo. Dele falar: venha aqui vamos tentar entender, vamos ver onde você tem dificuldade. Vamos ver o que nós podemos fazer pra te ajudar.

[E4] Eu não gosto do jeito de dar aula do prof. ZO. Ele [é] meio quietão assim, mas tem hora que fala; mas fica meio vago.

[E6] Que nem a gente estava tendo aula de termoelétrica com esse professor, nossa eu não estava entendendo nada, aí eu falava: Meu Deus que aula chata!

Como podemos observar, para E3, além de o professor ser "gente boa", ele realizava o atendimento "de um jeito que parecia que você estava entendendo". Porém, diversas vezes os comentários sobre as aulas de professores não são positivos. E4 não gostava do "jeito de dar aula" de um de seus professores, enquanto que E6 considerava a aula de termoelétrica "chata".

\section{Célula 1c}

A célula 1c diz respeito aos valores, preceitos, crenças etc., que o estudante partilha com grupos e comunidades em que vive, a partir dos quais avalia o ensino que o professor pratica. Mas, além disso, o estudante em geral também prescreve 
as atitudes e comportamentos que considera que o professor precisa ter em sala de aula.

[E4] Acredito que primeiro de tudo [o professor] tem que saber ensinar. [...] Não ser turrão. [...] E também ter um bom relacionamento com o aluno.

[E5] Olha, bom professor [...] ele tem que gostar dos alunos. Só que pra fazer... pra ele fazer gostar dos alunos o aluno tem que gostar dele.

[E6] Eu acho que pra ser um bom professor assim, ele deve manter essa relação com o aluno, só que não pode dar muito espaço, entende? Porque assim, tem algumas aulas assim que o professor é amigo do aluno e ele consegue dar aula, e consegue ao mesmo tempo ser amigo da turma. E tem professor que quando ele abre muito essa relação com os alunos o professor não consegue mais dar aulas, os alunos se sentem muito assim, é a gente que manda, entende?

Usualmente, o estudante utiliza os verbos "ter" e "dever" para expressar suas opiniões ou percepções a respeito das células que pertencem à linha social. E4, com base em suas experiências com diversos professores, seus métodos de ensino, chega a um conjunto de valores ("saber ensinar", "não ser turrão" e "ter um bom relacionamento com o aluno") que caracterizariam, em sua opinião, um bom professor. Os estudantes E5 e E6 mencionam que o professor deve "gostar do aluno" e ser "amigo", com duas ressalvas: para E5, primeiro o aluno tem de gostar do professor, para que este goste do aluno; e para E6, o professor "não pode dar muito espaço", pois corre o risco de se ver dominado pela turma.

\section{Percepções/ações dos estudantes a respeito de sua aprendizagem (coluna 2)}

A coluna 2 (que corresponde ao segmento E-S do triângulo) é a principal coluna da Matriz do Estudante, pois cabe a ele, essencialmente, aprender, ou seja, se envolver em uma prática do saber, conforme já mencionado. Como no caso anterior, nesta coluna foram inseridas as percepções dos estudantes a respeito de sua aprendizagem sob três perspectivas: epistêmica (célula 2a); pessoal (célula 2b); social (célula 2c).

\section{Célula 2a}

A célula 2 a diz respeito ao pensamento do estudante sobre o conteúdo que está aprendendo e à sua própria aprendizagem. O estudante percebe suas facilidades e suas dificuldades de aprendizagem com as disciplinas escolares, cria estratégias de estudo e recorre a outros para aprender.

[E1] História é meu problema. Não é que eu não vá bem, mas eu não consigo decorar as datas, decorar e entender História.

[E3] Números você não precisa escrever e é algo fácil de você entender a lógica. Uma ou duas palavras do enunciado, não completo, você consegue entender a lógica do que pede. Aí você compara com a regra ortográfica, uma palavra você escreve de um jeito, daí você pega e vale pra algumas e não todas. E daí já me quebra as pernas, porque daí eu tenho que decorar duas regras pra mesma função.

No caso dos estudantes entrevistados, em geral, a reflexão que desenvolvem sobre sua aprendizagem envolve uma comparação entre disciplinas diferentes. Para E1 História é um problema, porque ele não consegue "decorar as datas". Já para E3, enquanto que os números são "algo fácil de entender", as regras 
ortográficas lhe "quebram as pernas". Usualmente, os estudantes comentam também sobre as estratégias que utilizam para melhorar sua aprendizagem. Por exemplo: "parar, sentar" para estudar, não deixar para última hora ou pedir ajuda a alguém, no caso de E1 (depoimento a seguir); ou então prestar bastante atenção na explicação do professor e discutir com ele depois, no caso de dúvida, que é o que faz E5 (próximo relato):

[E1] Mas aí que nem, Matemática, Química, Física, eu tenho que parar, sentar, caso eu não esteja conseguindo entender a matéria [...] e não deixar pra última hora porque senão eu não consigo. Eu tento pedir ajuda pro professor, e se eu vejo que eu não tô conseguindo, eu tento falar com alguém, com algum aluno, porque sabe, às vezes é mais fácil um aluno explicar do que um professor.

[E5] Eu sou boa de memorizar muito bem, e tem a questão da leitura também, é o que me ajuda bastante. Eu fico muito quieta às vezes na sala [...] porque eu vendo o pensamento dos outros eu evoluo o meu também. Então quando o professor chega assim na sala, e ele começa apresentar alguma coisa nova principalmente, eu presto muita atenção e eu vou discutir sobre aquilo e eu vou mostrar o meu ponto de vista, porque é aí que eu aprendo muito.

\section{Célula $2 b$}

A célula $2 b$ diz respeito ao sentido que o estudante atribui ao conteúdo que está aprendendo e à sua própria aprendizagem. O estudante demonstra emoções positivas ou negativas a respeito do conteúdo, de forma usual, vinculando tais emoções e interesses diretamente à sua aprendizagem.

[E1] Quando eu não consigo aprender, eu fico nervosa.

[E2] É, eu nunca gostei de gramática, desde pequenininha... Mas eu sempre fui bem em Matemática, desde pequena. Na verdade eu gosto [de Matemática] porque eu acho que é muito interessante, e eu tenho facilidade, e isso também me leva a gostar.

[E3] Eu gosto mais de números... Por incrível que pareça eu gosto de Física e Matemática e matérias técnicas que envolva cálculo.

[E4] Eu gostava de Matemática. Porque eu me dava bem. Eu gostava porque eu ia bem.

[E5] Eu gosto de aprender aquilo que eu me interesso, entende?

[E6] [...] eu gosto de estudar. Quando eu não aprendo, tipo parece que a matéria fica chata, é uma coisa que parece que eu não tenho vontade de estudar. Desmotiva um pouco. E quando eu aprendo, nossa! Eu tenho muita vontade de estudar e tenho muita vontade de fazer, principalmente cálculo, porque eu gosto de cálculo. Só que quando eu não consigo fazer, nossa me desmotiva muito, só que quando eu começo a fazer que eu aprendo, eu pego jeito e fico pensando, nossa!! Consegui fazer o cálculo sozinha...

Todos os estudantes entrevistados, em algum momento, comentaram a respeito de sua aprendizagem do ponto de vista dos sentimentos, emoções, sentidos, desejos e interesses que estas suscitam. E1, por exemplo, fica "nervosa" quando não consegue aprender. Como aconteceu na célula $1 \mathrm{~b}$, em seus comentários, utilizam principalmente o verbo gostar. Então E2 nunca gostou de gramática, mas gosta e vai bem em Matemática; E3 gosta mais de "números"; E3 
também "gostava" de Matemática; E5 gosta de aprender; e E6 gosta de estudar. A vinculação entre as emoções positivas pelo conteúdo e a facilidade ou consciência da aprendizagem desse conteúdo, também, aparecem em quase todos os depoimentos: o estudante gosta da disciplina porque vai bem (E4) ou, quando não aprende, a "matéria fica chata" e, então, fica sem vontade de aprender (E6).

\section{Célula 2c}

A célula $2 c$ diz respeito aos valores relacionados à aprendizagem. O estudante atribui valores ao conteúdo que está aprendendo, utiliza princípios e normas para orientar sua ação no que diz respeito à sua própria aprendizagem, percebe o caráter social da aprendizagem e associa os saberes escolares a uma profissão que deseja exercer futuramente. É importante lembrar que os saberes aqui são também saberes profissionais, e não apenas o conteúdo puro, como já dissemos.

[E1] Mas assim, eu tenho que correr atrás, se eu for mal, eu tenho que fazer a recuperação.

[E2] Tem uns [alunos] que são mais largados e eles querem aprender. Tipo não vou prestar atenção na aula, mas eu vou aprender e isso não acontece porque se você não prestar a atenção você não vai aprender. As coisas não caem assim do céu. Não vêm por osmose, se dormir não vai aprender.

[E3] E nessa mudança de Ensino Fundamental para o Ensino Médio foi onde eu comecei a trabalhar. Onde comecei a ter um empreguinho, e eu vi que não era tão bom trabalhar. Então eu vi que as pessoas que tinham um pouco mais de estudo eram aquelas que trabalhavam menos e ganhavam mais. Então eu coloquei pra mim, eu vou ter que estudar um pouquinho mais pra mim, não poder, vamos supor, sofrer tanto.

Frases como "eu tenho que correr atrás" (E1), "se você não prestar a atenção você não vai aprender" ou "As coisas não caem assim do céu" (E2) ou "eu vou ter que estudar um pouquinho mais" (E3) são exemplos de que os estudantes demonstram a valorização da aprendizagem, até porque "as pessoas que tinham um pouco mais de estudo eram aquelas que trabalhavam menos e ganhavam mais", como diz E3. Ainda, nesta célula, estamos incluindo as falas que associam o conteúdo ou uma disciplina a uma profissão ou a um curso universitário. É o caso das duas falas seguintes:

[E5] Acho que eu vou usar [a Matemática] em determinado momento da minha vida. Algumas coisas de Matemática com certeza eu não vou usar porque eu não vou pra área de Matemática, então..., mas os caras que vão fazer engenharia vão.

[E6] Que nem, você faz uma engenharia, você pode seguir vários caminhos assim, você não tem que trabalhar especificadamente em uma área... eu posso dar aula, eu posso trabalhar em uma fábrica, não só na engenharia mecânica, eu posso ir para outros setores também.

O conteúdo pode ter um valor profissional para a vida futura do estudante. São exemplos: a frase "Algumas coisas de Matemática com certeza eu não vou usar porque eu não vou pra área de Matemática" de E5 e a frase "você faz uma engenharia, você pode seguir vários caminhos" de E6. Há ainda um terceiro tipo de frases que podemos incluir nesta célula: aquelas que evidenciam o caráter social da aprendizagem, que em geral envolvem as menções que o estudante faz de seus colegas e da classe como um todo: 
[E3] O primeiro ano foi difícil, porque eu não conhecia ninguém, ninguém, ninguém. No primeiro dia de aula parecia que todo mundo se conhecia e eu não. Daí eu falei: ué, mas eu vou ficar aqui, quietão, parado? Depois fui fazendo amizade com um, com outro... Com os trabalhos que eu fui [fazendo amizade]... porque eu era obrigado a ter que conversar... E eu fui pra um grupo... depois eu pulei pra outro, e pra outro. Eu sou aquele cara que roda a sala inteira.

[E4] [...] a amizade era importante. Ter amigos na escola me ajudava, me ajudava no sentido de que se não tivesse amizade eu talvez não tivesse a mesma motivação assim. Eu ia ser desmotivado.

O ensino e a aprendizagem são atividades relacionais. O "outro" - como professor ou colega - está sempre presente na sala de aula, seja fisicamente, seja como "fantasma do outro", como diz Charlot (2000, p. 46). São exemplos: a frase "O primeiro ano foi difícil, porque eu não conhecia ninguém, ninguém, ninguém" ou "porque eu era obrigado a ter que conversar", ambas de E3, em que ele faz menção ao fato de ter de trabalhar em grupo; ou a frase "[...] a amizade era importante. Ter amigos na escola me ajudava", evitando que E4 ficasse desmotivado.

\section{Percepções/ações dos estudantes sobre a relação do professor com os saberes escolares e/ou profissionais (coluna 3 )}

Finalmente, na coluna 3, estão acomodados os pensamentos, sentimentos e valores com os quais o estudante avalia a relação do professor com os saberes escolares e profissionais. Usualmente, o estudante não separa de forma clara as relações do professor com o ensino que pratica das relações que ele mantém com os saberes. Ou seja, saber um conteúdo para o estudante, muitas vezes, é inseparável do saber ensinar e, em geral, ao falar da relação do professor com o conteúdo e os saberes profissionais (coluna 3 ) ele acaba dizendo mais da relação do professor com o ensino desses saberes (coluna 1). Por isso, a quantidade de falas na coluna 1 foi maior do que na coluna 3 . No entanto, entendemos que o campo da relação do professor com o saber (segmento P-S) é diferente do campo da relação do professor com o ensinar (segmento P-E). É isso que nos mostra o triângulo didático-pedagógico da Figura 1.

\section{Célula $3 a$}

A célula 3a diz respeito ao pensamento do estudante sobre a relação do professor com o conteúdo, ou, de um modo mais geral, com o saber profissional. O estudante percebe claramente se o professor sabe, domina um conteúdo ou os saberes da sua profissão, ou seja, se o professor tem uma relação positiva ou negativa com os saberes profissionais:

[E1] [...] porque na escola estadual tem um monte de professor de Português que está dando aula de Matemática, aula de Química, e ele não entende.

[E2] Teve um só [que eu não gostei], um professor de Matemática. É que ele não era formado em Matemática [...]. E ele não sabia nem explicar a matéria, nem fazer as contas. Teve uma vez que ele errou uma conta no quadro e eu briguei com ele, então depois disso ele passou a me odiar então.

Embora o estudante fique envolvido emocionalmente com a relação do professor com o conteúdo, ele está avaliando de maneira epistêmica essa relação ao afirmar que o professor "não entende" a matéria (E1) ou que o professor "não 
sabia nem explicar" (E2). Os estudantes também avaliam se o professor investe em seu desenvolvimento profissional. Isso é o que demonstra a fala do estudante E5:

[E5] [...] aqui do Instituto Federal, que vê um professor com uma estrutura legal para o trabalho com um pensamento assim, mais avançado, na questão que mostra o que sabe, entende, que está estudando para melhorar. Tem muitos professores da rede pública, [...] tem muito professor que vai lá, pede pra aumentar o salário e não estudam mais, se acomodam.

\section{Célula 3b}

Diz respeito ao sentido que o estudante atribui à relação do professor com o conteúdo e a profissão. O estudante percebe o interesse e o envolvimento do professor com o conteúdo e a profissão:

[E1] [...] e também por eles terem gosto da profissão, gosto de ser professor. Porque a gente vê o professor que gosta de ser professor e outros que estão sendo só pra ganhar.

Nas entrevistas encontramos apenas um exemplo em que o sentido da frase é direto. Contudo, nas frases da célula anterior, podemos inferir que a relação pessoal dos professores apontados naqueles casos também não era positiva.

\section{Célula 3c}

Está relacionada ao valor que o estudante atribui à relação do professor com o conteúdo e com os saberes profissionais. O estudante atribui valores à relação positiva do professor com o conteúdo e com a profissão e, ainda, percebe os valores que circulam na sociedade e nas comunidades em que vive.

[E1] Então se ele [o professor] gosta da matéria que ele tá dando e ele entende então isso é o principal.

[E5] Olha, bom professor tem que gostar daquilo que faz. [...] e ele tem que gostar da matéria, porque daí ele vai falar da matéria com empolgação, tipo aquelas coisas que não está falando, das coisas do livro que a gente estuda na sala, mas sim do que está na internet.

Gostar da matéria que ensina, ou gostar da profissão, são dois dos principais valores que os estudantes atribuem ao professor, como nas falas de E1 e E5. Assim como nas células da linha c, anteriores, os estudantes usualmente utilizam os verbos "ter" e "dever" para expressar os princípios que regem suas ações. Em outros momentos, eles simplesmente apontam para os valores que a sociedade aceita, como na fala de E2.

[E2] [...] o meu sonho é ser professora de Matemática [...]. Eu acho que, professor de Matemática [...] é menos valorizado pela cultura brasileira. Mas, tem oportunidades tanto quanto [engenharia]. Porque se formar em Matemática, você vai trabalhar, isso é certeza, vai ter algum lugar.

E ainda, na fala "quero que vocês sejam independentes" (E1), vemos que ele se refere a um valor que seu professor expressou e com o qual o estudante concorda. 


\section{DESCRITORES}

Como indicado, a Matriz do Estudante, mostrada no Quadro 2, é um instrumento de pesquisa que permite a categorização das falas e das ações dos estudantes em sala de aula. Precisamos agora detalhar, descrever pormenorizadamente as células desta matriz. Isso já começou a ser realizado na seção anterior. Com a ajuda dos dados, a partir das frases selecionadas das entrevistas com os seis estudantes, nós chegamos a uma descrição preliminar de cada uma delas. Essa descrição pode e precisa, no entanto, ser generalizada para que o instrumento proposto possa ser aplicado em outros contextos. Refletindo sobre as análises realizadas na seção anterior chegamos ao seguinte conjunto de descritores, que representam o nosso principal metatexto:

Descritores da Coluna 1 - Percepções/ações dos estudantes a respeito do professor e seu ensino (segmento E-P)

Célula 1a. Diz respeito ao pensamento do estudante sobre o ensino praticado pelo professor. Inclui a compreensão do estudante sobre os procedimentos didático-pedagógicos que o professor adota, de seus objetivos de ensino, de suas avaliações, de sua racionalidade nas correções das provas, trabalhos etc. Diz respeito à busca por parte do estudante de razões objetivas que expliquem a ação do professor em sala de aula e deem racionalidade ao seu ensino.

Célula $1 b$. Diz respeito ao sentido que o estudante atribui ao ensino praticado pelo professor. Ao seu envolvimento e interesse quanto aos procedimentos didático-pedagógicos que o professor adota e seu estilo de ensino. Como o estudante sente o modo como o professor se relaciona com ele e com os demais estudantes. $\mathrm{O}$ quanto o estudante gosta ou não gosta da aula e do professor; o quanto quer ou não permanecer neste ensino. Trata-se do sentido que o estudante atribui à sala de aula e às relações interpessoais que nela ocorrem.

Célula 1c. Diz respeito ao valor que o estudante atribui ao ensino praticado pelo professor. Inclui suas crenças a respeito do papel do professor e do ensino, enquanto atividade social e interativa; o quanto partilha de discursos, procedimentos e valores que o aproximam ou o afastam do ensino, do professor e da escola.

Descritores da Coluna 2 - Percepções/ações dos estudantes a respeito de sua aprendizagem (segmento E-S)

Célula $2 a$. Diz respeito ao pensamento do estudante sobre o conteúdo ou, de uma forma mais geral, aos saberes profissionais, que está aprendendo e à sua própria aprendizagem. Como ele compreende e utiliza os principais conceitos, explicações, argumentos, modelos, teorias e fatos científicos criados para a compreensão do mundo natural. Como percebe e reflete sobre seu próprio desenvolvimento cognitivo, sobre sua aprendizagem das disciplinas. Inclui as maneiras como realiza e avalia sua aprendizagem; que ações e estratégias o estudante adota para aprender mais e resolver suas dificuldades de aprendizagem seja recorrendo aos livros, ao professor ou a colegas; a sua relação com os materiais instrucionais, livros, experimentos, instrumentos e outras fontes de saber; as maneiras como realiza o planejamento de sua aprendizagem e seu desenvolvimento escolar.

Célula $2 b$. Diz respeito ao sentido que o estudante atribui ao conteúdo que está aprendendo e à sua própria aprendizagem. O quanto gosta ou não gosta dos 
saberes escolares e quanto se identifica como aprendiz. Relaciona-se ao desejo de saber e aprender; ao seu interesse, envolvimento emocional e curiosidade para aprender sobre fenômenos do mundo natural e sobre o mundo escolar; a como se autoavalia como estudante e como sua aprendizagem o afeta emocionalmente; como trabalha suas inseguranças em relação às suas dificuldades de aprendizagem; ao sentido pessoal que atribui ao ato de aprender e quanto isso influi em sua identidade como aprendiz.

Célula 2c. Diz respeito ao valor que o estudante atribui ao conteúdo que está aprendendo, ao aprendizado enquanto um valor em si, que o induz e o mobiliza para aprender mais. Inclui seus sentimentos em relação à aprendizagem, enquanto atividade social e interativa; às dificuldades e inseguranças pessoais em relação à própria aprendizagem, produzidas em decorrência da interação com os outros (colegas, pais, professores, administradores etc.). Inclui suas crenças a respeito do papel da escola e da aprendizagem em sua vida profissional futura; o quanto partilha de discursos, procedimentos e valores que o aproximam ou o afastam de uma aprendizagem real e duradoura.

Descritores da Coluna 3 - Percepções/ações dos estudantes sobre a relação do professor com os saberes profissionais (segmento P-S)

Célula 3a. Diz respeito ao pensamento do estudante sobre a relação do professor com o conteúdo. Se o professor demonstra conhecimento a respeito dos principais conceitos, explicações, argumentos, modelos, teorias e fatos científicos da disciplina que ensina, nas aulas e nas avaliações. Se o professor transmite domínio e segurança pessoal em relação ao conteúdo. Se o professor demonstra ter conhecimento dos locais em que o conteúdo pode ser encontrado, como livros, bibliotecas, mídias, internet etc.

Célula 3b. Diz respeito ao sentido que o estudante atribui à relação pessoal do professor com o conteúdo. Se o professor gosta/não gosta e demonstra envolvimento e interesse com a disciplina que ministra. Ao sentido que o conteúdo adquire para o professor e o quanto determina sua identidade profissional. Se o professor busca aprender sempre mais sobre o conteúdo que ministra.

Célula 3c. Diz respeito ao valor que o estudante atribui à relação do professor com o conteúdo. Se o professor dá valor à sua formação, se procura melhorá-la. Se o professor partilha de uma comunidade de educadores e dos eventos que esta realiza. Se ele mantém relação com as pessoas e instituições que detêm o conhecimento (outros professores, escolas, Universidades). O quanto ele partilha de discursos, procedimentos e valores que o aproximam ou o afastam do conteúdo e de sua profissão. A relação do professor com o conteúdo e com a profissão pode apontar valores e influenciar o estudante.

\section{CONSIDERAÇÕES FINAIS}

Nesse artigo apresentamos a Matriz do Estudante. Ela foi criada para ser um instrumento de análise das relações do estudante com o saber no triângulo didático-pedagógico. Estamos particularmente interessados em entender as percepções e ações do estudante em sala de aula, visto que o ato de aprender é singular, é uma ação do sujeito.

Em sua utilização na pesquisa esta matriz permite categorizar um texto, por exemplo, uma entrevista, ou a descrição da ação que o estudante realiza em sala de aula. Com isso poderemos formar um quadro geral das percepções e/ou ações 
que o estudante apresenta durante uma atividade, durante uma aula, durante uma disciplina etc.

Para elucidar um pouco mais esta nossa proposição, cremos que o processo de categorização pode ser auxiliado pelo conjunto de questões apresentado a seguir, elaborado a partir dos dados que sustentam essa investigação e dos descritores das células da Matriz do Estudante:

Coluna 1

a. O professor sabe ensinar? $\mathrm{O}$ estudante aprende com esse professor? $\mathrm{O}$ professor ensina de forma coerente, lógica e planejada?

b. O professor gosta de ensinar? O estudante gosta das aulas desse professor? O estudante participa das aulas? As aulas são interessantes ou são chatas? O estudante gosta do professor (de sua pessoa)?

c. O professor dá valor ao seu ensino? O estudante valoriza as aulas desse professor? As aulas do professor são boas? O professor é considerado um bom professor?

Coluna 2

d. O estudante sabe o conteúdo? O estudante está aprendendo o conteúdo? Aprender esse conteúdo é fácil ou difícil? O estudante está estudando o suficiente?

e. O estudante gosta do conteúdo? Aprender esse conteúdo é prazeroso ou é chato? $\mathrm{O}$ estudante tem interesse em aprender e se mobiliza para isso? $\mathrm{O}$ estudante se identifica com a posição de aprendiz?

f. O estudante dá valor ao conteúdo? Aprender esse conteúdo tem algum valor? Essa disciplina (ou conteúdo) será útil futuramente?

Coluna 3

g. O professor sabe o conteúdo? Demonstra domínio da matéria?

h. O professor gosta do conteúdo? Procura aprender mais sobre a matéria, quando não domina algum assunto? O professor demonstra interesse em se desenvolver mais como professor?

i. O professor dá valor ao conteúdo? O professor se identifica com a profissão? Quais valores são induzidos pela relação do professor com o conteúdo e a profissão?

Para encerrar queremos dizer que este instrumento, que já está sendo utilizado nas pesquisas de mestrados e doutorados em andamento no nosso grupo de pesquisa, foi inspirado em uma publicação anterior (ARRUDA; LIMA; PASSOS, 2011), na qual apresentamos um instrumento para a análise da ação docente em sala de aula.

\section{Agradecimentos}

Agradecemos ao CNPq e à Fundação Araucária pelo apoio financeiro durante todo o desenvolvimento desta pesquisa. 


\title{
A tool for analyzing the students perceptions/actions in classroom
}

\begin{abstract}
The objective of this article is to present a research instrument that allows to investigate the relationship with knowledge of students in the classroom. The instrument, called Learning Matrix, considers the classroom as a complex system of epistemic, social and personal relations with the knowledge to be taught, the teacher's work in classroom and student learning. The article also presents data gathered with students from one of the campuses of the Federal Institute of Paraná. The data presented in this article, however, are intended to provide experimental consistency to arguments that give theoretical support to the instrument. The article concludes with descriptors from each of the nine cells of the matrix and a set of guiding questions for future research.
\end{abstract}

KEYWORDS: Relationship with knowledge. Didactic and pedagogical triangle. Learning matrix. 


\section{REFERÊNCIAS}

ARRUDA, S. M.; LIMA, J. P. C.; PASSOS, M. M. Um novo instrumento para a análise da ação do professor em sala de aula. Revista Brasileira de Pesquisa em Educação em Ciências, v. 11, p. 139-160, 2011.

ARRUDA, S. M.; PASSOS, M. M. A relação com o saber na sala de aula. Trabalho apresentado no IX Colóquio Internacional "Educação e Contemporaneidade". Mesa-redonda: Relação com o Saber e o Ensino de Ciências e Matemática. São Cristóvão, SE, 18 de setembro de 2015.

http://educonse.com.br/ixcoloquio/arruda_passos2.pdf.

CHARLOT, B. Da relação com o saber: elementos para uma teoria. Porto Alegre: Artmed, 2000.

Formação de professores: a pesquisa e a política educacional. In: Pimenta, S. G.; Ghedin, E. Professor reflexivo no Brasil: gênese e crítica de um conceito. São Paulo: Cortêz, 2005a.

Relação com o saber, perspectiva dos professores e a globalização. Porto Alegre: Artmed, 2005b.

GAUTHIER, C.; MARTINEAU, S.; DESBIENS, J. F.; MALo, A.; SIMARD, D. Por uma Teoria da Pedagogia: pesquisas contemporâneas sobre o saber docente. ljuí: Unijuí, 2006.

GAUTHIER, C.; TARDIF, M. A pedagogia: teorias e práticas da antiguidade aos nossos dias. Petrópolis: Vozes, 2013.

ILLERIS, K. Uma compreensão abrangente da aprendizagem humana. In: Illeris, K. (Org.). Teorias contemporâneas da aprendizagem. Porto Alegre: Penso, p. 15-30, 2013.

LAVE, J. A prática da aprendizagem. In: Illeris, K. (Org.). Teorias contemporâneas da aprendizagem. Porto Alegre: Penso, p. 235-245, 2013.

MORAES, R.; GALIAZZI, M. Análise textual discursiva. Ijuí: Unijuí, 2007. 
POPPER, K. Conhecimento objetivo. Belo horizonte: Itatiaia, 1975.

Recebido: 2016-07-16

Aprovado: 2017-07-10

DOI: 10.3895/rbect.v10n2.445

Como citar: ARRUDA, S. DE M.; BENÍCIO, M. A.; PASSOS, M. M. Um instrumento para a análise das percepções/ações de estudantes em sala de au. Revista Brasileira de Ensino de Ciência e Tecnologia, v. 10 n. 2, 2017. Disponível em: <https://revistas.utfpr.edu.br/rbect/article/view/4457>. Acesso em: xxx.

Correspondência:

Direito autoral: Este artigo está licenciado sob os termos da Licença Creative Commons-Atribuição 4.0 Internacional. 